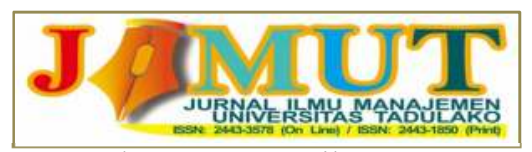

Vol. 7, No 2, April 2021, 117-126

\title{
ANALISIS SISTEM ANTRIAN LOKET PENDAFTARAN PESERTA PADA BADAN PENYELENGGARAAN JAMINAN SOSIAL KESEHATAN KOTA PALU
}

\author{
Raudatul Hasanah \\ Sulaeman Miru \\ Program Studi S1 Manajemen, Fakultas Ekonomi dan Bisnis, Universitas Tadulako \\ email: raudha27041997@gmail.com ; sulaimanmiru@gyahoo.co.id
}

\begin{abstract}
This study aims to analyze the system of registration counter queues in the organization of health social security (BPJS) at Palu city. This research is descriptive with purposive sampling technique of sampling. As many as 30 ware taken.The results of this study are the registration counter queue system in (BPJS) in Palu city by using a queue type, and a single channel single phase, using the queing model $M / M / 1$, with service discipline following the model FCFS (first come first served). The average service time is 13,72033333 minute/customer.
\end{abstract}

Key word: Queuing system, counter, BPJS

\begin{abstract}
Abstrak
Penelitian ini bertujuan untuk menganalisis sistem antrian loket pendaftaran pada Badan Penyelenggaraan Jaminan Sosial Kesehatan (BPJS) di Kota Palu. Penelitian ini bersifat deskriptif dengan teknik pengambilan sampel secara sampling purposive. Sampel yang diambil sebanyak 30 sampel yang diambil dari hasil penelitian dalam antrian BPJS. Hasil penelitian ini yaitu sistem antrian loket pendaftaran pada Badan Penyelenggaraan Jaminan Sosial Kesehatan (BPJS) Di Kota Palu dengan menggunakan jenis antrian Single Channel Single Phase untuk model antrian menggunakan Model M/M/1 dengan disiplin pelayanan mengikuti model FCFS (First Come First Served). Rata-rata waktu pelayanan yaitu sbesar 13,72033333 menit/peserta.
\end{abstract}

\section{Kata kunci : Sistem Antrian, Loket, BPJS}

\section{PENDAhULUAN}

Sistem antrian merupakan keseluruhan dari proses para peserta atau barang yang berdatangan yang memasuki barisan antrian yang seterusnya memerlukan pelayanan sebagaimana seharusnya berlaku. Dalam mempelajari suatu sistem antrian, perlu untuk diketahui struktur sistem antrian, yaitu unit yang memerlukan pelayanan disebut pelanggan (customer) dan yang melayani disebut pelayanan (serve). (A M H Pardede et al., 2014)

Badan Penyelenggaraan Jaminan Sosial Kesehatan (BPJS) merupakan Badan Usaha Milik Negara yang di tugaskan khusus oleh pemerintah untuk menyelenggarakan jaminan pemeliharaan kesehatan bagi seluruh rakyat Indonesia, terutama untuk Pegawai Negeri Sipil (PNS) dan TNI/POLRI, Perintis Kemerdekaan beserta keluarganya dan Badan Usaha lainnya ataupun rakyat biasa. Kantor Badan Penyelenggaraan Jaminan Sosial Kesehatan (BPJS) kesehatan Cabang Utama di Kota Palu. Kantor ini mengembangkan tanggung jawab untuk memberikan pelayanan pada masyarakat Kota Palu.

Badan Penyelenggaraan Jaminan Sosial Kesehatan (BPJS) terdapat 5 loket yang ditempatkan pada sistem antrian untuk melayani para pesertanya yang ingin melakukan pembuatan kartu BPJS, ganti kartu, ubah data faskes, kartu hilang, keluhan dan informasi. Namun dalam pelayanan hanya ada 1 loket yang dioperasikan oleh kantor BPJS Kota Palu untuk pembuatan kartu BPJS. Hal ini 


\section{JMMT}

Vol. 7, No 2, April 2021, 117-126

mengakibatkan, sering terjadi penumpukan antrian yang cukup banyak dan peserta membutuhkan waktu lama untuk menunggu giliran mendapatkan pelayanan.

Sistem antrian timbul disebabkan oleh kebutuhan akan layanan yang melebihi kapasitas atau fasilitas pelayanan yang tersedia. Untuk memberikan layanan yang prima bagi para pesertanya di perlukan suatu sistem layanan yang handal dengan melakukan efisiensi waktu pelayanan. Apabila masalah antrian ini tetap dibiarkan oleh piha-pihak kantor BPJS Kota Palu, maka ini akan merugikan pihak perusahaan. Kemungkinan yang akan timbul adalah peserta merasa dirugikan karena banyaknya waktu yang terbuang begitu saja selama menunggu yang pada akhirnya meninggalkan antrian. Selain itu pihak BPJS pun secara tidak langsung mengalami kerugian, karena akan mengurangi efisiensi kerja, keuntungan yang sedikit, dan bahkan akan menimbulkan citra kurang baik pada pesertanya.

\section{KAJIAN LITERATUR}

Teori antrian adalah teori yang menyangkut studi matematis dari antrian atau baris-baris penungguan. Teori antrian berkenan dengan seluruh aspek dan situasi peserta (baik orang maupun barang) harus antri untuk mendapatkan suatu layanan. Menurut Heizer dan Render (2009) antrian adalah ilmu tentang bentuk antrian dan merupakan orang-orang atau barang dalam barisan yang sedang menunggu untuk dilayani atau meliputi bagaimana perusahaan dapat menentukan waktu dan fasilitas yang sebaik-baiknya agar dapat melayani pelanggan dengan efisien.

Menurut Heizer dan Render (2006:659) terdapat tiga komponen dalam sebuah sistem antrian yaitu: (1) kedatangan atau masukan sistem (2) disiplin antrian atau antrian itu sendiri dan (3) fasilitas pelayanan. Menurut Kakiay (2004:13) ada beberapa struktur dalam sistem antrian yaitu sebagai berikut:

1. Struktur antrian single channel single phase adalah struktur antrian yang paling sederhana.

2. Struktur Single Channel Single Phase yaitu memiliki satu jalur pelayanan sehingga menunjukkan bahwa ada dua atau lebih pelayanan yang dilaksanakan secara berurutan

3. Struktur multiple channel single phase yaitu terjadi ketika dua atau lebih fasilitas layanan digunakan oleh antrian tunggal.

4. Struktur Multi cahnnel MultiPhase yaitu mempunyai beberapa fasilitas pelayanan pada setiap tahapnya, sehingga lebih dari satu pelanggan dapat dilayani pada satu waktu.

Terdapat empat model antrian yang paling sering digunakan dalam sistem operasional perusahaan (Heizer dan render, 2006:666). Model antrian dapat membantu perusahaan dalam mengoptimalisasi pelayanan seperti menentukan waktu pelayanan dan menentukan jumlah saluran antrian. Empat model sistem antrian tersebut adalah sebagai berikut:

\section{1. $\mathrm{M} / \mathrm{M} / \mathrm{I}$}

Pada model ini sistem antrian yang digunakan menggunakan pola kedatangan berdistribusi poisson dan pola pelayanan berdistribusi eksponsial dengan jumlah server satu, kapasitas sistem tidak terbatas, sumber pemanggilan tak terbatas serta disiplin pelayanan yang digunakan adalah fisrt in fisrt out. Model antrian M/M/1 dengan satu server, yang dapat digunakan sebagai pendekatan untuk berbagai sistem antrian sederhana.

2. Model $\mathrm{M} / \mathrm{M} / \mathrm{S}$

Model antrian M/M/S disebut juga model antrian jalur berganda yaitu model dimana terdapat dua atau lebih jalur atau stasiun pelayanan untuk melayani untuk menangani peserta yang datang.

3. Model M/D/1 


\section{JMMT}

Vol. 7, No 2, April 2021, 117-126

Model M/D/1 merupakan model dengan waktu pelayanan yang konstan. Model ini diasumsikan memiliki jalur pelayanan tunggal dengan pola tingkat kedatangan mengikuti distribusi poisson dan pola waktu pelayanan konstan.

4. Model Populasi Terbatas

Model ini berada dari ketiga model antrian yang telah dijelaskan sebelumnya, karena dalam model ini terjadi hubungan saling ketergantungan antara panjang antrian dan tingkat kedatangan.

Efisiensi adalah suatu rasio dari aktual output suatu proses yang biasanya dilakukan dengan relatif, untuk beberapa ukuran standar. Secara alternatif, ukuran efisiensi umumnya dipergunakan untuk mengukur keberhasilan atau kerugian dalam suatu proses. Efisiensi adalah kemampuan untuk menyelesaikan suatu pekerjaan dengan benar. Ini merupakan konsep matematik atau merupakan perhitungan rasio antara keluaran (output) dengan masukan (input)

\section{METODE PENELITIAN}

\section{Jenis Penelitian}

Penelitian ini termasuk penelitian dengan metode deskriptif studi kasus. Studi Kasus yaitu penelitian terhadap kasus, peristiwa, dan proses pelayanan peserta pada Badan Penyelenggaraan Jaminan Sosial (BPJS). Penelitian deskriptif adalah penelitian yang bertujuan untuk mendeskripsikan sifat sesuatu yang tengah berlangsung pada saat penelitian dilakukan.

\section{Lokasi Penelitian}

Penelitian dilakukan pada Badan Penyelenggaraan Jaminan Sosial Kesehatan (BPJS) di Kota Palu Sulawesi Tengah

\section{Populasi}

Populasi dalam penelitian ini adalah seluruh pengunjung BPJS di Kota Palu yang datang dan melakukan pendaftaran kartu BPJS pada loket yang sudah disediakan

\section{Sampel}

penarikan sampel dari populasi dilakukan dengan mengacu pada metode pengambilan sampel sampling purposive. Sampling purposive adalah teknik penentuan sampel dengan pertimbangan tertentu, ukuran sampel yang layak dalam penelitian adalah antara 30 sampai 500 (Sugiyono, 2014:122)

\section{Jenis dan Sumber Data}

Ada dua jenis data yang digunakan dalam penelitian ini yaitu data kuantitatif dan data kualitatif, dijelaskan sebagai berikut:

\section{Data Kuantitatif}

Data Kuantitatif yaitu data terukur berupa angka-angka, jumlah maupun hasil perhitungan yang diperoleh langsung dari perusahaan yang akan di olah lebih lanjut secara sistematis. Data kuantitatif yang digunakan dalam penelitian ini berupa data kedatangan peserta BPJS per satuan waktu, dan data tingkat pelayanan rata-rata per satuan waktu.

\section{Data Kualitatif}

Data kualitatif adalah data yang bersifat sistematik, narasi atau uraian yang tidak dapat dihitung. Data kualitatif yang digunakan dalam penelitian ini seperti data hasil wawancara, keterangan mengenai gambaran umum perusahaan dan keterangan lain yang berhubungan dengan antrian dan pelayanan pada Badan Penyelenggaraan Jaminan Sosial Kesehatan (BPJS) di Kota Palu. 


\section{JMMT}

Vol. 7, No 2, April 2021, 117-126

\section{Sumber Data}

Sumber data yang digunakan untuk memperoleh data kuantitatif dan data kualitatif dapat digolongkan menjadi dua jenis sumber data yaitu:

1. Data Primer

Data primer dalam penelitian ini adalah data yang diperoleh langsung dari hasil observasi pada objek penelitian data kedatangan peserta, data tingkat pelayanan per satuan waktu dan data pelayanan pada Badan Penyelenggaraan Jaminan Sosial Kesehatan (BPJS) di Kota Palu

2. Data Sekunder

Data sekunder dalam penelitian ini diperoleh dari hasil studi pustaka dan pencarian terhadap literatur terkait dengan tema penelitian seperti penelitian-penelitian terdahulu dan hasil penelitian kepustakaan.

\section{Metode Pengumpulan Data}

Untuk mengumpulkan data penelitian baik itu data kuantitatif maupun data kualitatif dari sumber data primer dan sekunder, peneliti menggunakan beberapa metode pengumpulan data sebagai berikut:

1. Observasi

Yaitu pengumpulan data yang dilakukan dengan cara pengamatan atau meninjau objek secara langsung untuk mencatat informasi yang berkaitan dengan masalah yang akan diteliti. Observasi dalam penelitian ini dilakukan untuk mengumpulkan data kedatangan peserta dan data tingkat pelayanan yang dicatat dalam kertas kerja.

2. Wawancara

Yaitu dengan melakukan tanya jawab langsung kepada pihak yang dianggap mampu memberi informasi terkait dengan masalah yang akan diteliti.

3. Dokumentasi

Yaitu dengan mengumpulkan data dari kumpulan arsip, laporan, dan dokumen perusahaan yang berhubungan dengan sistem pelayanan antrian.

\section{Definisi Operasional Variabel Penelitian}

Variabel penelitian ini adalah suatu atribut atau sifat atau nilai dari orang, objek atau kegiatan yang mempunyai variabel tertentu yang ditetapkan oleh peneliti untuk dipelajari. Dalam hal ini peneliti mengambil variabel yang terkait dengan penelitain sebagai berikut:

1. Tingkat Kedatangan

Tingkat kedatangan adalah jumlah rata-rata kedatangan peserta per periode waktu. Tingkat kedatangan dapat dihitung dengan membagi jumlah kedatangan peserta dengan waktu penelitian.

2. Tingkat pelayanan

Tingkat pelayanan adalah jumlah peserta yang dapat dilayani oleh loket per periode waktu. Tingkat pelayanan dapat dihitung dengan membagi jumlah waktu dalam satu periode dengan rata-rata waktu yang dibutuhkan untuk melayani satu peserta.

3. Karakteristik Antrian

Karakteristik Antrian adalah gambaran sistem antrian serta secara umum karakteristik antrian dapat dilihat dari beberapa aspek yaitu ukuran populasi, pola kedatangan, kepanjangan antrian, disiplin pelayanan, dan desain pelayanan.

4. Kinerja Antrian

Kinerja antrian adalah gambaran tingkat kesibukan sistem antrian. Kinerja antrian dapat dilihat dari hasil perhitungan rata-rata jumlah peserta dalam sistem $\left(L_{s}\right)$, rata-rata waktu yang 
dihabiskan dalam sistem $\left(W_{s}\right)$, rata-rata jumlah peserta berada dalam antrian $\left(L_{q}\right)$, rata-rata waktu yang dihabiskan dalam antrian $\left(W_{q}\right)$, probabilitas tidak ada peserta dalam sistem $\left(P_{o}\right)$, dan tingkat utilitas pelayanan $(\rho)$,

5. Optimalisasi Kasir

Optimalisasi kasir adalah penentuan jumlah kasir seharusnya digunakan dalam sistem agar pelayanan optimal. Optimalisasi kasir diperoleh dengan cara membandingkan kinerja antrian saat dilakukan penelitian dengan kinerja antrian dengan asumsi dilakukan penambahan jumlah kasir.

\section{Metode Analisis Data}

Dalam Menganalisis data, Percobaan dilakukan dengan menghitung kinerja dari sistem antrian pada Badan Penyelenggaraan Jaminan Sosial (BPJS) di Kota Palu dengan menggunakan 1 loket dan model antrian yang peneliti gunakan menggunakan model $\mathrm{M} / \mathrm{M} / 1$ Hasil perhitungan kinerja antrian yang terbaik merupakan jawaban dari permasalahan. Beberapa hal yang diperhitungkan dalam mengukur kinerja suatu antrian yakni:

1. Rata-rata banyak peserta dalam $\operatorname{sistem}\left(L_{s}\right)$

$$
\mathrm{L}_{\mathrm{s}}=\frac{\lambda}{\mu-\lambda}
$$

2. Rata-rata waktu yang dihabiskan peserta dalam sistem $\left(W_{s}\right)$

$$
\mathrm{W}_{\mathrm{s}}=\frac{1}{\mu-\lambda}
$$

3. Rata-rata banyak peserta dalam $\operatorname{sistem}\left(L_{q}\right)$

$$
\mathrm{L}_{\mathrm{q}}=\frac{\lambda^{2}}{\mu(\mu-\lambda)}
$$

4. Rata-rata yang dihabiskan peserta dalam $\operatorname{sistem}\left(W_{q}\right)$

$$
\mathrm{W}_{\mathrm{q}}=\frac{\lambda}{\mu(\mu-\lambda)}
$$

5. Probabilitas tidak ada peserta dalam $\operatorname{sistem}\left(P_{o}\right)$

$$
P_{O}=1-\frac{\lambda}{\mu}
$$

6. Faktor utilisasi dalam sistem (P)

$$
\mathrm{P}=\frac{\lambda}{\mu}
$$

7. probabilitas terdapat $\mathrm{K}$ peserta dalam sistem, dimana $\mathrm{n}$ adalah jumlah peserta dalam system $\left(P_{n>k}\right)$

$$
P_{n>k}=\left(\frac{\lambda}{\mu}\right)^{k+1}
$$

\section{HASIL DAN PEMBAHASAN}

Badan Penyelenggaraan Jaminan Sosial Kesehatan (BPJS) memiliki 5 loket untuk melayani peserta yang akan melakukan pembuatan kartu BPJS, ganti kartu, ubah data fasilitas kesehatan, kartu hilang, keluhan dan informasi. Namun dalam pelayanan hanya ada 1 loket yang dioperasikan oleh kantor BPJS Kota Palu untuk pembuatan kartu BPJS. Hal ini dikarenakan pihak BPJS menganggap 1 loket sudah efisien untuk melayani peserta, peserta banyak melakukan pendaftaran 


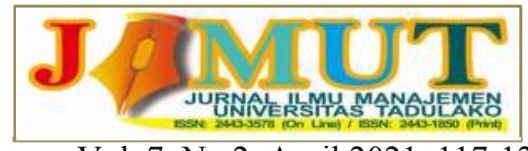

Vol. 7, No 2, April 2021, 117-126

pembuatan kartu BPJS pada hari senin dan jumat. Dari hasil pengamatan peneliti terhadap sistem antrian yang diterapkan oleh Badan Penyelenggaraan Jaminan Sosial Kesehatan (BPJS) Kota Palu.

Pengumpulan data yang dilakukan dalam penelitian ini adalah pengumpulan data melalui metode observasi. Observasi dilakukan secara langsung pada loket pendaftaran pembuatan kartu BPJS. Observasi dilakukan selama 20 hari, yaitu pada tanggal 2-3, 6-10, 13-17, 20-24, 27-29 Mei 2019, Selain itu untuk melakukan pengumpulan data pada Badan Penyelenggaraan Jaminan Sosial Kesehatan (BPJS) jamnya terbagi dalam 2 bagian yaitu jam 08.00-12.00 WITA dan jam 13.0015.00 WITA.

Untuk memperoleh data rata-rata tingkat kedatangan peserta, dibutuhkan data jumlah kedatangan peserta pada loket pendaftaran pembuatan kartu BPJS di Kota Palu. Data kedatangan peserta BPJS pada waktu pengamatan dibagi menjadi dua bagian yaitu jam 08.00-12.00 WITA dan jam 13.00-15.00 WITA, dapat dilihat pada table berikut:

Tabel 1.1

\section{Data Kedatangan Peserta pada Loket}

Pendaftaran Pembuatan Kartu BPJS di Kota Palu (orang)

\begin{tabular}{clcc}
\hline \multirow{2}{*}{ No } & Hari/Tanggal & \multicolumn{2}{c}{ Waktu Kedatangan } \\
& & $\mathbf{0 8 . 0 0 - 1 2 . 0 0}$ & $\mathbf{1 3 . 0 0 - 1 5 . 0 0}$ \\
\hline 1 & Kamis, 2 Mei 2019 & 20 & 19 \\
2 & Jumat, 3 Mei 2019 & 40 & 13 \\
3 & Senin, 6 Mei 2019 & 29 & 20 \\
4 & Selasa, 7 Mei 2019 & 30 & 17 \\
5 & Rabu, 8 Mei 2019 & 22 & 9 \\
6 & Kamis, 9 Mei 2019 & 15 & 10 \\
7 & Jumat, 10 Mei 2019 & 36 & 6 \\
8 & Senin, 13 Mei 2019 & 32 & 17 \\
9 & Selasa, 14 Mei 2019 & 16 & 15 \\
10 & Rabu, 15 Mei 2019 & 27 & 9 \\
11 & Kamis, 16 Mei 2019 & 14 & 13 \\
12 & Jumat, 17 Mei 2019 & 45 & 5 \\
13 & Senin, 20 Mei 2019 & 25 & 18 \\
14 & Selasa, 21 Mei 2019 & 30 & 8 \\
15 & Rabu, 22 Mei 2019 & 30 & 17 \\
16 & Kamis, 23 Mei 2019 & 26 & 10 \\
17 & Jumat, 24 Mei 2019 & 38 & 16 \\
18 & Senin, 27 Mei 2019 & 33 & 12 \\
19 & Selasa, 28 Mei 2019 & 21 & 15 \\
20 & Rabu, 29 Mei 2019 & $\mathbf{5 6 3}$ & 16 \\
\hline & Jumlah & & 16 \\
\hline
\end{tabular}

Sumber: Badan Penyelenggaraan Jaminan Sosial Kesehatan (Hasil Observasi)

Berdasarkan perhitungan diatas, dapat diketahui bahwa rata-rata tingkat kedatangan pelanggan di Bdan Penyelanggaraan Jaminan Sosial Kesehatan (BPJS) di Kota Palu memiliki jumlah yang berbeda, dapat dilihat pada Tabel sebagai berikut: 
Table 4.2

Rekapitulasi Rata-Rata Tingkat Kedatangan Per Jam (orang)

\begin{tabular}{ccc}
\hline \multirow{2}{*}{ Periode Waktu } & \multicolumn{2}{c}{ Rata-Rata Tingkat Kedatangan } \\
& Hasil Perhitungan & Dibulatkan \\
\hline $08.00-12.00$ & 7,0375 & 7 \\
$13.00-15.00$ & 6,625 & 7 \\
\hline
\end{tabular}

Sumber: Badan Penyelenggaraan Jaminan Sosial Kesehatan (Diolah Kembali)

Untuk mengetahui rata-rata tingkat pelayanan, terlebih dahulu ditentukan rata-rata waktu pelayanan. Rata-rata waktu pelayanan merupakan jumlah waktu pelayanan yang diberikan dalam waktu tertentu. Data waktu pelayanan diperoleh dari hasil observasi dengan mencatat lama waktu yang dibutuhkan loket untuk melayani pelanggan. Pencatatn dilakukan dengan mengambil 30 sampel pelanggan secara acak, dapat dilihat pada table sebagai berikut:

Tabel 4.3

Data Waktu pelayanan Pelanggan di Loket Badan Penyelenggaraan Jaminan Sosial Kesehatan (BPJS) di Kota Palu

\begin{tabular}{|c|c|c|}
\hline $\begin{array}{l}\text { Pelanggan } \\
\text { (orang) }\end{array}$ & $\begin{array}{c}\text { Waktu Kedatangan } \\
\text { (Menit) }\end{array}$ & $\begin{array}{c}\text { Waktu Pelayanan } \\
\text { (Menit) }\end{array}$ \\
\hline 1 & 9.53 & 14.83 \\
\hline 2 & 21.03 & 17,76 \\
\hline 3 & 29.46 & 8.38 \\
\hline 4 & 12.21 & 16.25 \\
\hline 5 & 25.17 & 13.38 \\
\hline 6 & 31.09 & 7.78 \\
\hline 7 & 20.55 & 15.54 \\
\hline 8 & 15.05 & 19.48 \\
\hline 9 & 27.41 & 7.21 \\
\hline 10 & 24.25 & 14.84 \\
\hline 11 & 17.59 & 7.36 \\
\hline 12 & 19.01 & 18.25 \\
\hline 13 & 11.19 & 15.57 \\
\hline 15 & 32.25 & 20.19 \\
\hline 16 & 22.01 & 8.37 \\
\hline 17 & 30.21 & 15.42 \\
\hline 19 & 28.44 & 7.47 \\
\hline 20 & 25.07 & 13.45 \\
\hline 21 & 8.49 & 21.34 \\
\hline 22 & 17.41 & 19.08 \\
\hline 23 & 33.26 & 6.77 \\
\hline 24 & 30.05 & 8.83 \\
\hline 25 & 21.34 & 23.46 \\
\hline 26 & 26.11 & 15.57 \\
\hline 27 & 28.27 & 11.35 \\
\hline 28 & 37.4 & 16.44 \\
\hline 29 & 19.31 & 10.75 \\
\hline 30 & 20.12 & 14.34 \\
\hline \multicolumn{2}{|c|}{ Jumlah } & 411.61 \\
\hline
\end{tabular}

Sumber: Badan Penyelenggaraan Jaminan Sosial Kesehatan (Hasil Observasi) 
Berdasarkan perhitungan di atas, dapat diketahui bahwa rata-rata tingkat pelayanan pelanggan di Badan Penyelenggan Jaminan Sosial Kesehatan (BPJS) memiliki jumlah yang berbeda, Pada peserta 1 yang datang pada BPJS setiap harinya terlebih dahulu mengambil nomor antrian dan setelah itu mengisi formulir yang telah disediakan untuk membuat/mendaftar pembuatan kartu BPJS dan setelah itu duduk di kursi antrian selama 9,53 menit hingga dilayani pada loket selama 14,83 menit hingga proses pendaftaran selesai, begitu juga pada peserta 2 sampai peserta 20, dapat dilihat pada Tabel 4.4 


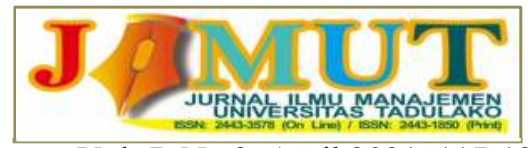

Vol. 7, No 2, April 2021, 117-126

Table 4.4

Rekapitulasi Rata-Rata Tingkat Pelayanan Per Jam (orang)

\begin{tabular}{lcc}
\hline \multirow{2}{*}{ Periode Waktu } & \multicolumn{2}{c}{ Rata-Rata Tingkat Kedatangan } \\
& Hasil Perhitungan & Dibulatkan \\
\hline $08.00-12.00$ & 17,49228639 & 17 \\
$13.00-15.00$ & 8.746143194 & 9 \\
\hline
\end{tabular}

Sumber: Badan Penyelenggaran Jaminan Sosial Kesehatan (Hasil Observasi)

Berdasarkan perhitungan diatas, dapat diketahui bahwa kinerja antrian loket Badan Penyelenggaraan Jaminan Sosial Kesehatan (BPJS) dengan menggunakan 1 loket dapat dilihat pada Tabel 4.5

Table 4.5

Hasil Kinerja Sistem Antrian Loket BPJS dengan Menggunakan 1 Loket

\begin{tabular}{cccccccc}
\hline $\begin{array}{c}\text { Periode } \\
\text { Waktu }\end{array}$ & $\mathbf{L}_{\mathbf{s}}$ & $\mathbf{W}_{\mathbf{s}}$ & $\mathbf{L}_{\mathbf{q}}$ & $\mathbf{W}_{\mathbf{q}}$ & $\boldsymbol{P}_{\boldsymbol{o}}$ & $\mathbf{P}$ & $\boldsymbol{P}_{\boldsymbol{n}>\boldsymbol{k}}$ \\
\hline $08.00-12.00$ & 0.7 & 0,1 & 28,823 & 4,1176 & 0,5882 & 0,4117 & 0,1695 \\
$13.00-15.00$ & 3,5 & 0,5 & 10,8889 & 1,5556 & 0,2222 & 0,7778 & 0,6049
\end{tabular}

Sumber: Badan Penyelenggaraan Jaminan Sosial Kesehatan (Diolah Kembali)

Dengan melihat hasil diatas, jumlah loket yang diterapkan oleh Badan Penyelenggaraan Jaminan Sosial Kesehatan (BPJS) sudah efektif, dengan melihat waktu rata-rata pelanggan menunggu dalam antrian sebesar 4,1176 menit yang berarti hamper tidak adanya pelanggan menunggu untuk antri, ini terjadi pada periode waktu 08.00-12.00, serta antrian terpanjang sebanyak 28,823 orang atau dibulatkan 29 orang yang berarti banyaknya pelanggan yang menunggu dalam antrian, ini terjadi pada periode waktu 08.00-12.00. Dan melihat dari tingkat kesibukan (utilisasi) loket pendaftaran pada periode waktu 13.00-15.00 yaitu sebesar 0,7778 atau $77,78 \%$.

\section{KESIMPULAN DAN SARAN}

1. Sistem antrian pada Badan Penyelenggaraan Jaminan Sosial Kesehatan (BPJS) yang saat ini menggunakan 5 loket akan tetapi penulis hanya meneliti 1 Loket saja dalam pembuatan kartu BPJS atau pendaftaran kartu BPJS.

2. Rata-rata waktu pelayanan loket yaitu 13,72033333 menit/pelanggan. Dan standar waktu pelayanan yang ditetapkan oleh Badan Penyelenggaraan Jaminan Sosial Kesehatan (BPJS) di Kota Palu yaitu selama 15 menit, dapat dikatakan waktu pelayanan loket Badan Penyelenggaraan Jaminan Sosial Kesehatan (BPJS) sudah efisien dengan melihat tingkat utilitasnya sebesar 0,7778 atau $77,78 \%$

3. Sistem antrian pada loket Badan Penyelenggaraan Jaminan Sosial Kesehatan memiliki karakteristik ukuran populasi tidak terbatas, kedatangan cenderung acak dan berkelompok, panjang antrian tidak dibatasi, disiplin pelayanan mengikuti pola FCFS (First Come First Served), desain Single Channel Single Phase, dan waktu pelayanan acak.

4. Untuk melihat dari segi usaha dalam efisien pada Badan Penyelenggaraan Jaminan Sosial Kesehatan (BPJS) di Kota Palu memberikan perbandingan yang terbaik dilihat 


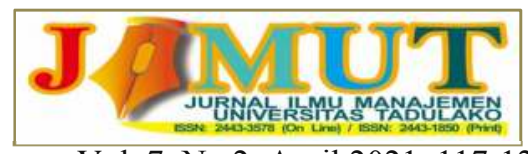

Vol. 7, No 2, April 2021, 117-126

dari sudut usaha yaitu sudah mengeluarkan 5 sumber kerja untuk mencapai hasil tertentu yang diharapkan dan ke lima sumber itu adalah pikiran, tenaga, waktu, ruang dan benda. Dan untuk melihat dari segi hasil dalam efisien sudah menunjukkan perbandingan yang terbaik ditinjau dari sudut hasil dan sudah memberikan hasil yang paling besar mengenai jumlah atau mutunya.

Berdasarkan kesimpulan di atas maka penulis dapat memberikan saran kepada Badan Penyelenggaraan Jaminan Sosial Kesehatan (BPJS) di Kota Palu. yaitu untuk dapat memepertahankan atau dapat meningkatkan kuliatas pelayanan terhadap pelanggan BPJS pada loket pendaftaran BPJS agar pelayanan dapat berjalan lebih efisien.

\section{REFERENSI}

Gie, The Liang. 1992. Cara Bekerja Efisien. Yogyakarta: Liberty

Heizer, J. dan Render, B. 2006. Operations Management. Edisi 7. Jakarta: Salemba Empat.

Handoko. 1998. Manajemen. Yogyakarta :BPFE

Hartono.2011. Metode Penelitian. (Pekanbaru: Zanafa, 2011), hlm: 46

Heizer dan Render, 2006 Operations Manajement, English Edition, Pearson Education, New Jersey

Heizer, Jay and Bany, Render. (2009). Operation Manajement. Terjemahan oleh Dwianoegrawati Setyaningsih \& Indra Almahdy. Edisi 7. Buku I. Salemba empat, Jakarta.

Ishak, Aulia, 2010. Manajemen Operasi, Graha Ilmu, Yogyakarta

Pardede, A.M.H., Mawengkang, H., \& Situmorang, Z. (2014). Simulasi Antrian Berdatangan Berkelompok Dengan Pelayanan Weibull Oleh Banyak Server. Jurnal Teknologi Informasi Dan Komunikasi, 3(1), 1-10

Rustam.2012. Analisis Penerapan Sistem Antrian Model M/M/S Pada PT. Bank Negara Indonesia (PERSERO) Tbk. Kantor Cabang Pembantu Universitas Hasanuddin Makassar. Jurnal.Makassar: Fakultas Ekonomi dan Bisnis Universitas Hasanuddin Makassar. 